\title{
Differentiation Strategy and Performance of Long-distance Bus Companies in Kenya
}

\author{
Orucho Michael Ngala ${ }^{1} \&$ Chemutai Patricia ${ }^{2}$ \\ ${ }^{1}$ School of Business and Economics, The Co-operative University of Kenya, Nairobi, Kenya \\ ${ }^{2}$ School of Management and Leadership, The Management University of Africa, Nairobi, Kenya \\ Correspondence: Orucho Michael Ngala, School of Business and Economics, The Co-operative University of \\ Kenya, Nairobi, Kenya, P.O BOX 24814-00502, Karen, Nairobi, Kenya. E-mail: oruchomiko@gmail.com
}

Received: July 3, 2019

Accepted: August 7, 2019

Online Published: September 5, 2019

doi:10.5539/ijbm.v14n10p146

URL: https://doi.org/10.5539/ijbm.v14n10p146

\begin{abstract}
Safe transport is an essential element to the development of an economy of any country. Transport enables movement of people, services and goods, from one location to another one. In Kenya, majority of the population who travel beyond three hundred (300) kilometres commonly use long distance bus service. Travelling for a long distance in a poorly maintained bus can be quite uncomfortable. Some buses are normally over-packed with hard seats, poor ventilation, overly slow or overly speedy and poor sanitation. Consequently, long distances need the most comfortable travelling medium to at least not get over exhausted. In product differentiation strategy, a firm seeks to be unique in its product offing compared to its competitors. This study sought to contribute to knowledge by assessing the influence of differentiation strategy on performance of long-distance bus companies in Kenya. Porter's generic strategies are the main model anchoring the study. Cross-Sectional survey was used as research design. The population of the study consists of fifty one (51) registered and licensed long distance bus companies in Kenya. Primary and secondary data were collected by the use of a structured questionnaires and review of regulatory bodies' websites and availed documents. Correlation and regression analyses were used to test hypotheses. Not all organizational performance determinants were included but balanced score card was appropriately used to reflect non-financial and financial indicators. Results show that safety strategy has the most significant influence on performance of long-distance bus companies in Kenya. This was followed by comfort and reliability respectively. The significance of safety measures when it comes to transporting people is quite critical. The central recommendation that the study offers as impetus to strategic management body of knowledge, transport companies and policy makers is the need to consider safety measures as the most essential differentiating features in transport management in order to win the confidence and loyalty of passengers thus enhance performance. The major limitation of this study is that primary data was gathered from three (3) bus company managers only per company. However, additional secondary data was used to validate primary data hence reduce common bias.
\end{abstract}

Keywords: differentiation, generic strategies, transport, long distance buses, performance

\section{Introduction}

\subsection{Research Problem}

Transport is a critical element to the development of an economy of any country. In Kenya, majority of the population who travel beyond three hundred (300) kilometres commonly use long distance bus service. In a product differentiation strategy an organization intends to be peculiar in its product offing compared to its competitors. These unique product characteristics should be widely valued by buyers (Porter, 1980). A firm therefore selects one or a number of characteristics that buyers perceive as important and uniquely positions it to meet the needs of the buyers in an industry. According to Ouma and Oloko (2015), long distance buses cover at least three hundred (300) kilometers on one trip. Travelling for a long distance in a poorly maintained bus can be quite uncomfortable. Some buses are normally over-packed with hard seats, poor ventilation, overly slow or high speed and poor sanitation. Consequently, long distances need the most comfortable travelling medium to at least not get over exhausted. Given the changing technological advancements and enhanced competition in the transport industry, it has been tricky for organizations which do not undertake product differentiation strategies to survive in an environment with such consistent changes and complexities. According to Bolade (1998) in his 
research on operations strategies pursued by inter-urban public service vehicles (PSV) bus companies in Kenya, public service bus companies acknowledge that differentiation strategies reinforce their competitive position, thus leading to superior performance. The study further established that, the main product differentiation priorities on which PSV bus firms compete include, customer care reliability, quality, fare incentives and flexibility. Safe, timely and comfortable transport system is therefore paramount for winning the loyalty of customers, consequently leading to superior performance in an organisation. According to Ouma and Oloko (2015), on their study of the relationship between generic strategies and competitive advantage among bus companies operating between Kisumu and Nairobi Kenya, the main differentiation strategies among long distance buses should revolve around Safety, reliability and comfort. However, this study did not demonstrate the most significant differentiating strategy among the three. The study also did not establish the relative strength of each strategy in influencing competitive advantage of the long-distance buses. According to Barney (2002), not all strategies have equal magnitude in advantage creation and that organisations need to identify and emphasise on the most significant competitive advantage creating resource that would lead to superior organisational performance. This study specifically established the influence of differentiation strategy on performance of long-distance buses in Kenya. Among, the three identified strategies as safety, comfort and reliability, the study sought to determine the relative strength of each strategy and hence the most significant determinant of organisational performance.

\subsection{Generic Strategies}

Porter (1996) came up generic strategies which he referred to as differentiation, cost leadership and market focus. The generic strategies are of paramount importance for organizations to gain valuable insights from customers' needs and to attain and sustain competitive advantage. There are two basic types of competitive advantage a firm can possess: low cost or differentiation. The two fundamental types of competitive advantage plus the scope of activities for which a firm needs to achieve them yield the three generic strategies for attaining supernormal performance within an industry. Market focus strategy has both differentiation focus and cost focus. Low cost and differentiation strategy may be compatible approaches in dealing with competitive forces. An organization may attain average returns in an industry despite the presence of strong competitive forces if it focuses on overall cost leadership (Barney, 2002). Even though, this strategy needs high relative market share, favorable access to raw materials, stable cash flow to purchase the most efficient equipment and such like advantages. Market Focus strategy on the other hand, is a strategy of segmenting markets and appealing to only a narrow group or single segment of consumers. This approach enables a firm to limit its attention to one or just a few market segments that it can serve much better in a concentrated matter as compared to diversification where a number of market segments are served.

\subsection{Differentiation Strategy}

According to Pearce \& Robinson (2011), differentiation strategy is a business strategy that enables a firm to build competitive advantage with its product or service by having that product or service uniquely different from other available products or services available within a competitive industry. A product or service that is well differentiated should generally be hard to create and imitate by other competing firms. According to Porter (1980), differentiation strategy involves creating a market position that is generally unique or peculiar within an industry and that is sustainable over a relatively long period of time. Porter (2002) posited that differentiation can be based upon design or brand image. In Particular, organisations pursuing differentiation strategy are expected to create customer value by offering high quality and unique products supported by appropriate service at premium prices. Such firms also strive to create and market peculiar products or services for different customer groups in the industry. Such firms aim to establish a fulfilling environment for customer requirements in one or multiple product or service attributes. This enables such firms achieve customer loyalty and delight. Differentiation strategy creates a perception in the minds of customers that the products or services being offered by a particular firm possess superior attributes that are distinctive, unique or peculiar and better compared to those from competitors in terms of image, reputation, reliability, quality and design features. Differentiating image involve distinguishing features of a product or service that make the customer more sensitive toward the buying process. Secondly, differentiation created by the relationship between the firm and customers through product personalization and adaptation to characteristics that the buyer demands. Thirdly, differentiation can be attained by concentrating on relationship between functional departments or other firm's relationships such as mix distribution channels and after sales services. Firms that succeed in differentiating their products or services would succeed in setting a higher price than their competitors as they justify the high costs of being uniquely different or exemplary. Porter (1996) noted that advantages which benefit organisations implementing differentiation strategy refers to the realization of higher income compared to competitors due to 
quality, brand loyalty and lower demand elasticity of consumers. In Kenya, long distance buses differentiate their services in areas such as office location, scheduled operation times, reliability, refreshments, electronic facilities, entertainment, online booking systems and safety measures Ouma and Oloko (2015). The objective of the study was to determine if these differentiating passenger service features actually enhance organizational performance and their relative roles in that respect.

\subsection{Organizational Performance}

According to Kaplan (2010), performance refers to a combination of financial and non-financial indicators which present information on the level of achievement of strategic objective. Rust, Zahorik and Keiningham (2002) observed that, financial organizational performance can be enhanced by improving performance on quality aspects. Their study showed that organizations whose principles relate to quality are guided by focus on value creation for customer. As competition intensifies, the service organizations are coming under serious pressure to ensure that their value creation is above board. The study adopted a balanced score card approach to carry out its performance measurements. Traditionaly, performance measurement tools focused more on financial metrics. However, balanced score card focuses on four performance perspectives such as finance, customer, internal process, and learning and growth to offer a holistic performance point of view (Kaplan, 2010). The performance indicators used in this study include revenue generated from passengers, customer satisfaction index, market share and number of routes.

\subsection{Transport Companies in Kenya}

In Kenya there is a very extensive network of both long distance and short distance bus routes coverage. Most of the long-distance buses in Kenya connect Nairobi to the Coastal and Western regions. According to Ouma and Oloko (2015), buses are essentially operated by many private companies that offer unique levels of comfort, safety and timely passenger services. Buses are relatively affordable and available compared to local flights. In this context, a long-distance bus is defined as a PSV vehicle that makes long trips beyond 300KM and registered as such by National Transport and Safety Authority (NTSA). Apart from exclusively executive buses, bus trips in Kenya are not always offer restful experience for since hawkers would board the buses and cause congestion in already a small space while selling their commodities. Long-distance buses are normally infested by roving preachers and herbalists who would go shouting the entire journey making the passengers quite wary and uncomfortable (Ouma and Oloko, 2015). As opposed to low end market where key decision on which bus to take may majorly revolve around price, the high-end market consumers would typically prioritize safety, comfort and reliability (MOTC, Transformation of Road Transport Report, 2004). Ouma and Oloko (2015) noted that in the past, Kenya Bus Services (KBS), which is owned by the government, used to offer long-haul services to most major towns around the country. They further noted that, although Kenya Bus Service (KEBS) tended to be relatively slower than buses operated by private companies, it tended to be safer compared to the private ones. By then, Akamba Bus had the most comprehensive network, and had relatively good safety record. Since then, several other companies have joined the industry with varying degrees of safety, comfort and reliability.

\subsection{Objectives of the Study}

The following objectives were formulated:

i) To determine the effect of safety strategy on performance of long-distance bus companies in Kenya.

ii) To establish the effect of comfort strategy on performance of long-distance bus companies in Kenya.

iii) To determine the effect of reliability strategy on performance of long-distance bus companies in Kenya.

iv) To establish the joint effect of differentiation strategies on performance of long-distance bus companies in Kenya.

\subsection{Hypotheses of the Study}

The following hypotheses are derived from the literature debate:

Hypothesis 1: There is significant relationship between safety strategy and performance of long-distance bus companies in Kenya.

Hypothesis 2: There is significant relationship between comfort strategy and performance of long-distance bus companies in Kenya.

Hypothesis 3: There is significant relationship between reliability strategy and performance of long-distance bus companies in Kenya.

Hypothesis 4: There is significant joint influence of differentiation strategies on performance of long-distance 
bus companies in Kenya.

\subsection{Conceptual Framework}

As illustrated in the conceptual model, differentiation strategies form independent variable while organizational performance forms dependent variable. The study established the direct relationship between differentiation strategies and organizational performance.

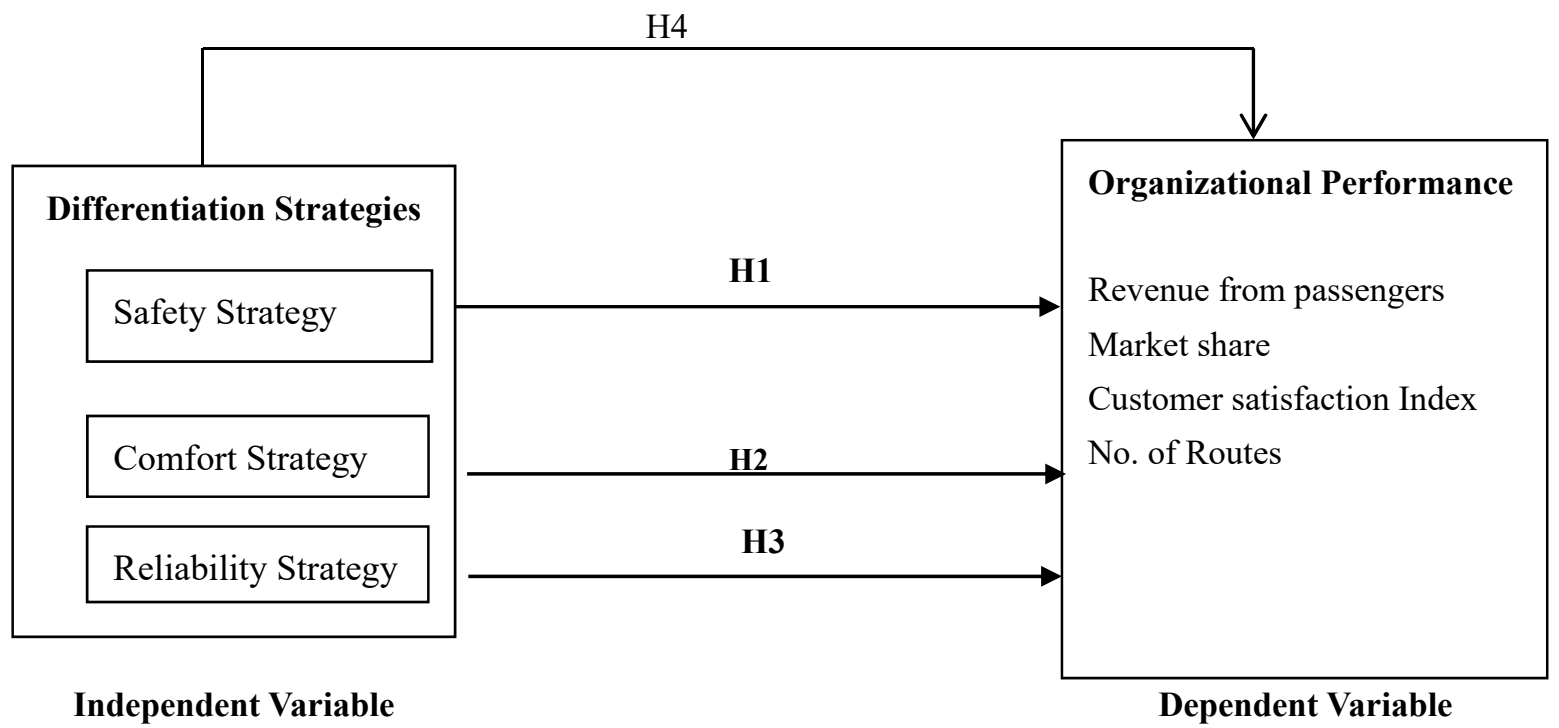

Figure 1. Conceptual model

\section{Method}

\subsection{Population and Respondents}

The population of the study consisted fifty one (51) long distance bus companies connecting Nairobi, Western and Coastal regions in Kenya. The study is a census of all long-distance bus companies registered by National Transport and Safety Authority were.

\subsection{Respondents}

During preliminary studies, the operation managers and route managers were identified as the key officers charged with the responsibility of identifying new routes and implementing strategies to increase turnover and profitability. Of course, the officers in charge of finance were also found critical in addressing matters related to financial performance. Consequently, from each company, three (3) officers (operation manager, route manager and finance officer) participated in the study. This implies that one hundred and fifty three (153) respondents were expected to participate in the study. However, out of the 153, only one hundred and twenty nine (129) questionnaires were returned. This constitutes a response rate of $84.3 \%$. Awino (2007) cited earlier scholars and stated that the average response rate for empirical studies was $65 \%$ of the sample. The results can therefore be generalized and considered representative of the population.

\subsection{Research Design}

Descriptive cross-sectional survey design was adopted in this study. The design approach involves collecting and comparing data from the phenomena as at the time of study. It employs both qualitative or quantitative data. The combination of qualitative and quantitative data enabled adequate explanation of the variables and predictions in the behavior of respondents without resorting into inquiries of the temporal effect. The chosen design was deemed appropriate for this study since it improved accuracy in generalizing findings. It involved detailed study of the unit selected in the study. The design enhanced uniform data collection and comparison across study respondents. The design was used to identify patterns of convergence that had developed to corroborate the overall interpretation of the relationships and interdependences among the study variables.

\subsection{Data Collection and Instrument}

Primary and secondary data were collected and used in the study. Primary data was obtained from the field as 
responses to the questionnaires which were distributed. The questionnaire items were developed from a wide review of literature from which ideas were moderated to suit the concepts and context of this study. The questionnaire for this study was thus designed on a five-point Likert-type scale. The responses were such that 1 was equated to No extent, 2 to small extent, 3 to moderate extent, 4 to large extent and 5to very large extent. According to Bryman and Bell (2007), a Likert scale is a psychometric scale normally involved in study that employs questionnaires under different scales. As opposed to larger scales, five-point Likert type scales are preferred when rating against one attribute such as familiarity of phenomenon being studied among respondents. The respondents completed semi-structured questionnaires by themselves over an agreed and specified period, after which the researcher picked the feedback. In other cases where appropriate, the respondents completed the questionnaires in the presence and under the guidance of the researcher. Secondary data was mainly obtained from existing records, especially financial aspects as tabulated by respondents.

\subsection{Reliability and Validity Tests}

Questionnaire was tested using expert judgement to verify accuracy of theoretical dimensions conceptualized in the study. Dess et al. (1993) noted that when a construct or a set of dimensions exhibits a strong content validity, there becomes a tendency among researchers to accept such without rigorous testing of other components of validity such as nomological, discriminant or convergent validity. This view was espoused the study. Reliability test for equivalence was undertaken through questionnaire pretesting by a pilot study of 5 randomly selected companies. According to Dillman (2000), a pilot study is conducted to ensure clarity and proper interpretation of data collection tool by the respondents. The feedback obtained from the respondents assisted to revise the scales and address the structure of the questions plus the overall design of the questionnaire. Consequently, a number of ambiguous questions were reconstructed and duplicated or repeated ones were deleted from the tool before administering the final revised version to the respondents. Nachmias and Nachmias (2004) noted that Cronbach's alpha coefficient is appropriate to use in testing the reliability of internal consistency of a research in which a Likert-type scale with multiple options is used to collect data. Reliability for the instrument used in this study was therefore tested using Cronbach's alpha coefficient to ensure internal consistency. According to Kline (1999) acceptable value for Cronbach's alpha is 0.7 or more. Cronbach's alpha coefficient was computed from the composite indices of all the independent and dependent variables used in the study. Each index was computed as the arithmetic mean obtained from all the respondents answering each part of the questionnaire. Cronbach's alpha scores for all variable were within acceptable ranges.

\subsection{Data Analysis}

Data collected was analyzed using descriptive and inferential statistics to provide simple summaries about the observations that were made. Descriptive statistical analysis was carried out through the use of mean values, standard deviations and frequencies. Kothari (2004) noted that descriptive statistics facilitate meaningful description of a distribution of scores or measurements using a few statistics or indices. Inferential statistics engaged include correlation and linear regression analyses to test the nature and directions of any existing relationships between independent and dependent variables, establish mathematical models relating variables and also test the formulated hypotheses.

The following mathematical models were formulated to establish regression equations relating independent and dependent variables:

$$
Y_{1}=\alpha_{1}+\beta_{1} X_{1}+e_{1}, Y_{2}=\alpha_{2}+\beta_{2} X_{2}+e_{2}, Y_{3}=\alpha_{3}+\beta_{3} X_{3}+e_{3}, Y_{4}=\alpha_{4}+\beta_{4} X_{1}+\beta_{5} X_{2}+\beta_{6} X_{3}+e_{4}
$$

Where: $X_{1}$ is safety strategy; $X_{2}$ is comfort strategy; $X_{3}$ is reliability strategy, $Y_{i}=Y_{1}, Y_{2}, Y_{3}$ and $Y_{4}$ which represents level of organizational performance. $\alpha_{i=} \alpha_{1}, \alpha_{2}, \alpha_{3}, \alpha_{4}$ which represent the level of performance when the effect of $X_{i}$ is zero. $\beta_{i}=\beta_{i}, \beta_{i}, \beta_{i}, \beta_{i}$ which represent the coefficient of $X_{i}$ while $e_{i}$ is the error term.

\section{Results}

Collected data were cleaned and coded, sorted, analyzed, interpreted and presented in tables as illustrated in this section. 


\subsection{The Influence of Safety Strategy on Performance of Long-Distance Bus Companies in Kenya}

Table 1. Correlation analysis results

\begin{tabular}{lll}
\hline Variable & Analysis & Performance \\
\hline Safety strategy & Pearson Correlation & $.860^{* *}$ \\
& Sig. (2-tailed) & .000 \\
& $\mathrm{~N}$ & 43 \\
Comfort Strategy & Pearson Correlation & $.826^{* *}$ \\
& Sig. (2-tailed) & .000 \\
& $\mathrm{~N}$ & 43 \\
Reliability Strategy & Pearson Correlation & $.652^{* *}$ \\
& Sig. (2-tailed) & .000 \\
& $\mathrm{~N}$ & 43 \\
\hline
\end{tabular}

Correlation analysis was undertaken after aggregating the variables as composite indices and by computing Pearson's product moment correlation coefficient (r). Results show that there exists high positive correlation between differentiation strategies and performance of bus companies in Kenya except for reliability which is moderately strong. Safety strategy and performance had the strongest relationship with $r=0.860$, which is greater than 0.7 as a rule of thumb and the correlation was found significant at $p$ value $(0.000)<0.01$ as shown in table 1 . This was followed by comfort strategy at 0.826 and lastly Reliability at 0.652 , which shows a moderate relationship between reliability strategy and performance since $0.652<0.7$. All the correlations are significant at $\mathrm{p}$ value $(0.000)<0.001$.

Table 2. Regression summary and ANOVA on Safety Strategy and company performance

\begin{tabular}{|c|c|c|c|c|c|}
\hline \multirow[b]{2}{*}{ Model } & \multicolumn{2}{|c|}{ Unstandardized Coefficients } & \multirow{2}{*}{$\begin{array}{l}\begin{array}{l}\text { Standardized } \\
\text { Coefficients }\end{array} \\
\text { Beta } \\
\end{array}$} & \multirow[b]{2}{*}{$\mathrm{t}$} & \multirow[b]{2}{*}{ Sig. } \\
\hline & $\mathrm{B}$ & Std. Error & & & \\
\hline (Constant) & .412 & .254 & & 1.620 & .113 \\
\hline \multirow[t]{2}{*}{ Safety strategy } & .746 & .069 & .860 & 10.791 & .000 \\
\hline & R Square & $\mathrm{df}$ & $\mathrm{F}$ & Sig. & \\
\hline Regression & & 1 & 116.447 & $.000^{\mathrm{b}}$ & \\
\hline Residual & & 41 & & & \\
\hline Total & .740 & 42 & & & \\
\hline
\end{tabular}

Note. Regression model is significant at the 0.001 level (2-tailed).

Regression analysis was undertaken to establish the mathematical model equations as between study variables. In order to fix potential collinearity problems, stepwise method of model selection was used so as to include only the most useful variables in the models. Safety strategy was then regressed with company performance and results summarized in Table 2. The model shows that safety strategy is a significant predictor of company performance $\left(\mathrm{Y}_{1}\right)$ with $\mathrm{p}$ value $(0.000)<0.001$ and $\mathrm{R}^{2}=.740$. The regression model relating safety strategy and company performance was established as $\mathrm{Y}_{1}=0.412+0.860 \mathrm{X}_{1}$. The model implies that a unit percentage increase in safety strategy would cause $0.860 \%$ increase in company performance. Table 2 shows that $\mathrm{F}(1,41)=$ 116.447 and $\mathrm{p}$ value $=.000<0.001$. Therefore, the regression model shows valid relationship between safety strategy and company performance. Consequently, the first research hypothesis was accepted as follows: Hypothesis 1: There is significant relationship between safety strategy and performance of long-distance bus companies in Kenya. 


\subsection{The Influence of Comfort Strategy on Performance of Long-Distance Bus Companies in Kenya}

Table 3. Regression Summary and ANOVA on comfort strategy and company performance

\begin{tabular}{|c|c|c|c|c|c|c|}
\hline \multirow[b]{3}{*}{ Model } & & \multicolumn{5}{|c|}{ Standardized } \\
\hline & & \multicolumn{2}{|c|}{ Unstandardized Coefficients } & \multicolumn{2}{|l|}{ Coefficients } & \multirow[b]{2}{*}{ Sig. } \\
\hline & & $\mathrm{B}$ & Std. Error & Beta & $\mathrm{t}$ & \\
\hline & (Constant) & .410 & .292 & & 1.403 & .168 \\
\hline & Comfort Strategy & .763 & .081 & .826 & 9.367 & .000 \\
\hline & & R Square & df & Mean Square & $\mathrm{F}$ & Sig. \\
\hline & Regression & & 1 & 21.856 & 87.737 & $.000^{\mathrm{b}}$ \\
\hline & Residual & & 41 & .249 & & \\
\hline & Total & .682 & 42 & & & \\
\hline
\end{tabular}

Note. Regression model is significant at the 0.001 level (2-tailed).

When comfort strategy was regressed with company performance as shown in table 3 , the model showed that comfort strategy is also a significant predictor of company performance $\left(\mathrm{Y}_{2}\right)$ with $\mathrm{p}$ value $(0.000)<0.001$ and $\mathrm{R}^{2}=.682$. The regression model relating comfort strategy and company performance was established as $\mathrm{Y}_{2}=0.410+0.826 \mathrm{X}_{2}$. The model implies that a unit percentage increase in comfort strategy would cause $0.826 \%$ increase in company performance.

Table 3 shows that $F(1,41)=87.737$ and $p$ value $=.000<0.001$, thus the regression model is a valid relationship between comfort strategy and company performance. Consequently, the second research hypothesis was also accepted as follows:

Hypothesis 2: There is significant relationship between comfort strategy and performance of long-distance bus companies in Kenya.

\subsection{The Influence of Reliability Strategy on Performance of Long-Distance Bus Companies in Kenya}

Table 4. Regression Summary and ANOVA on reliability strategy and company performance

\begin{tabular}{|c|c|c|c|c|c|c|}
\hline \multirow[b]{2}{*}{ Model } & & \multicolumn{2}{|c|}{ Unstandardized Coefficients } & \multicolumn{2}{|l|}{$\begin{array}{l}\text { Standardized } \\
\text { Coefficients }\end{array}$} & \multirow[b]{2}{*}{ Sig. } \\
\hline & & $\mathrm{B}$ & Std. Error & Beta & $\mathrm{t}$ & \\
\hline & (Constant) & .742 & .432 & & 1.718 & .093 \\
\hline & $\begin{array}{l}\text { Reliability } \\
\text { Strategy }\end{array}$ & .687 & .125 & .652 & 5.504 & .000 \\
\hline & & R Square & $\mathrm{df}$ & Mean Square & $\mathrm{F}$ & Sig. \\
\hline & Regression & & 1 & 13.628 & 30.299 & $.000^{\mathrm{b}}$ \\
\hline & Residual & & 41 & .450 & & \\
\hline & Total & .425 & 42 & & & \\
\hline
\end{tabular}

Note. Regression model is significant at the 0.001 level (2-tailed).

When reliability strategy was regressed with company performance as shown in table 3.4, the model showed that reliability strategy is also a significant predictor of company performance $\left(\mathrm{Y}_{3}\right)$ with $\mathrm{p}$ value $(0.000)<0.001$ and $\mathrm{R}^{2}=0.425$. The regression model relating reliability strategy and company performance was established as $\mathrm{Y}_{3}=0.742+0.652 \mathrm{X}_{3}$. The model implies that a unit percentage increase in reliability strategy would cause $0.652 \%$ increase in company performance. Table 4 shows that $F(1,41)=30.299$ and $p$ value $=.000<0.001$, thus the regression model is a valid relationship between reliability strategy and company performance. Consequently, the third research hypothesis was also accepted as follows:

Hypothesis 3: There is significant relationship between reliability strategy and performance of long-distance bus companies in Kenya. 


\subsection{The Influence of Differentiation Strategy on Performance of Long-Distance Bus Companies in Kenya}

Table 5. Regression Summary and ANOVA on Differentiation Strategy and Company Performance

\begin{tabular}{|c|c|c|c|c|c|c|}
\hline \multirow[b]{2}{*}{ Model } & & \multicolumn{2}{|c|}{ Unstandardized Coefficients } & \multicolumn{2}{|l|}{$\begin{array}{l}\text { Standardized } \\
\text { Coefficients }\end{array}$} & \multirow[b]{2}{*}{ Sig. } \\
\hline & & $\mathrm{B}$ & Std. Error & Beta & $\mathrm{t}$ & \\
\hline & (Constant) & .680 & .295 & & 2.309 & .026 \\
\hline & Safety & 1.098 & .317 & .266 & 3.460 & .010 \\
\hline & Comfort & .202 & .326 & .218 & .619 & .021 \\
\hline & Reliability & .243 & .153 & .230 & .590 & .023 \\
\hline & & R Square & $\mathrm{df}$ & Mean Square & $\mathrm{F}$ & Sig. \\
\hline & Regression & & 3 & 8.108 & 40.821 & $.000^{\mathrm{b}}$ \\
\hline & Residual & & 39 & .199 & & \\
\hline & Total & & 42 & & & \\
\hline
\end{tabular}

Note. Regression model is significant at the 0.05 level (2-tailed).

When all the three differentiation strategies were regressed as independent variables with company performance as dependent variable as shown in table 5, the model showed that differentiation strategies as combined composite of safety, comfort and reliability strategies is a significant predictor of company performance $\left(\mathrm{Y}_{4}\right)$ with $\mathrm{p}$ value $(0.000)<0.05$ and $\mathrm{R}^{2}=.758$. The regression model relating differentiation strategy and company performance was established as $\mathrm{Y}_{4}=0.680+0.266 \mathrm{X}_{1}+0.218 \mathrm{X}_{2}+0.230 \mathrm{X}_{3}$. Table 3.5 shows that $\mathrm{F}(3,39)=40.821$ and $\mathrm{p}$ value $=.000<0.05$, thus the regression model is a valid relationship between differentiation strategy and company performance. Consequently, the fourth research hypothesis was also accepted as follows:

Hypothesis 4: There is significant joint influence of differentiation strategies on performance of long-distance bus companies in Kenya.

\section{Discussion}

The findings of this study reaffirm findings by Ouma and Oloko (2015), who established that the main differentiation strategies among long distance buses should revolve around Safety, reliability and comfort. The study further established that safety strategy is the most significant among other differentiation strategies in influencing performance of long-distance bus companies in Kenya. Results show that safety strategy alone explains about $26 \%$ changes in performance level of bus companies. The implication is that majority of long-distance passengers consider safety measures as a matter of priority. The consequence of this passenger preference is that the safer the means of transport, the more bookings are made hence more revenue collected by the company. Specifically, the question on sufficient mechanisms in place to ensure that drivers strictly adhere to road and passenger safety rules had the highest frequency of respondents recording the highest score of very large extent of agreement. The issue of speed governors came second in the priority list of safety measures. Other priority aspects of safety as indicated by respondents include ensuring that drivers do not drive while drunk, well fitted seat belts and regular maintenance of buses after every trip. As conformed by Ouma and Oloko (2015), issues of comfort are also critical is determining the number of passengers booking a particular bus. The aspects of comfort which explained about $21 \%$ of bus company performance include appropriate and comfortable seats that customer needs, sufficient entertainment media such as display screens/Radio, free WIFI and functional electronics charging sockets, refreshments such as water or snacks provided to passengers, continual innovation and implementation of distinctive passenger comfort and delight measures. Last but not least, aspects of reliability also contributed about $23 \%$ in influencing bus company performance. Specific aspects of reliability strategies established by the study include online booking system, adherence to set bus time schedules, stable bus fare charges which do not frequently fluctuate, secure and accessible locations of booking offices, reliable measures in place to address customer complaints e.g working contacts, suggestion boxes and customer satisfaction surveys.

\section{Implications of the Study}

The study findings have theoretical, practical and policy implications for future researchers, long distance bus operators and all stakeholders. Porter's model of generic strategies as the main theory anchoring the study provides a favorable means of analyzing the appropriate strategies that can enhance performance of long-distance bus companies. The regression model linking differentiation strategies and company performance 
demonstrates the bus operators can apply the model in predicting performance of their companies. For practice, the study highlights the most significant components of differentiation strategies that impact on bus company performance. On policy matters, the study has established that safety issues come first in the passengers' list of priorities, followed by comfort and lastly reliability aspects. These findings thus provide critical insights to bus company managers, national transport and safety authority and other stake holders when formulating road transport management policies.

\section{Acknowledgments}

Completing this study was through the support of many individuals and institutions. I would like to sincerely thank all the bus company authorities who allowed me to collect data from their officers. The findings would not have been credible without participation of each and every company that took part in one way or another. Finally, this study would not have been successful without the involvement of experts, senior researchers and professionals who contributed immensely in questionnaire construction process. It could not be possible to mention every person who assisted me in one way or another but to all, I say thank you and may God bless you.

\section{References}

Barney, J. (2002). Gaining and Sustaining Competitive Advantage (2nd ed.), Upper Saddle River, NJ: Pearson Education

Bolade, T. (1998). Policy Reforms in the Urban Transport Sector in Nigeria. Urban Transport Policy: A Sustainable Development Tool. Proceedings of CODATU VIII Conference.

Dess, G., Newsport, S. \& Rasheed, A.M. (1993). Configuration Research in Strategic Management: Key Issues and Suggestions. Journal of Management, 19, 775-795.

Dillman, D. (2000). Mail and Internet Survey-The Tailored Design Method. New York: John Wiley and Sons, Inc.

Kaplan, R. S. (2010).Conceptual foundations of the Balanced Scorecard. Harvard Business School working paper, 10-74.

Kline, P. (1999). The Handbook of Psychological Testing. London. Routledge.

Kothari, C.R. (2004). Research Methodology: Methods and Techniques (2nd ed.). New Delhi: New Age International Limited.

Nachmias, C. F., \& Nachmias, D. (2004). Research Methods in the Social Sciences (5th ed.). Landon: Arnold.

Ouma, G., \& Oloko M. (2015). The Relationship between Porter's Generic Strategies and Competitive Advantage: A Case Study of Bus Companies Plying the Kisumu-Nairobi Route, Kenya. International Journal of Economics, Commerce and Management, 6, 1058-1092.

Porter, M. (1996). "What is strategy?" Harvard Business Review v74, n6 (Nov- Dec).

Porter, M. E. (1979). How competitive forces shape strategy. Harvard Business Review, 57(2), 137-145.

Porter, M. E., \& Millar, Victor E. (1985). How information gives you a competitive advantage. Harvard Business Review, 63(4), 149.

Rust, R. T., Zahorik A., J., \& Keiningham, L. T. (1995). Return on Quality (ROQ):Making Service Quality. Journal of Marketing, 59(April), 58-70.

\section{Copyrights}

Copyright for this article is retained by the author(s), with first publication rights granted to the journal.

This is an open-access article distributed under the terms and conditions of the Creative Commons Attribution license (http://creativecommons.org/licenses/by/4.0/). 